\title{
Management of central retinal detachment due to a macular hole
}

\author{
ABDEL-LATIF SIAM \\ Ophthalmology Department, Ein Shams University, Cairo, Egypt
}

Retinal detachment localized at the posterior pole is frequently due to macular holes, although it should be remembered that the majority of so-called macular holes are not true holes and therefore do not cause retinal detachment and do not require surgery or prophylactic coagulation.

Macular holes in cases of very high myopia, and particularly with posterior staphlomata and extensive macular chorioretinal atrophy and cystic degeneration, tend to be complete, and they then usually cause a central retinal detachment as has already been pointed out (Siam, 1969).

Nine more cases of central retinal detachment due to macular holes have been encountered since the last report of four cases was published, and these were all found in highly myopic eyes with posterior staphylomata. They represented less than I per cent. of the I,427 detachments seen during this period at the hospital clinic and in private practice. In none of the thirteen cases so far encountered have we found central retinal detachment without holes as reported by Phillips (1958) or holes other than macular as described by Regenbogen and Stein (I968); nor have we seen holes with opercula or horseshoe tears as recently reported byJungschaffer (I97I). Such cases, although rare, present insuperable difficulties to the surgeon; the prognosis is poor and the result is usually unsatisfactory even if the retina is successfully re-attached.

However, these unfortunate patients are nearly always very highly myopic with a deep posterior staphyloma and many have already lost the sight of one eye through retinal detachment. It was observed that those who were cured retained walking vision and appeared to be quite content with the result.

In this article it is proposed to discuss the current surgical techniques and to present our experience with such cases.

\section{SURGICAL TEGHNIQUES}

Earlier attempts at the surgical repair of macular holes include simple surface diathermy to the hole (Arruga, 1952) and transvitreal direct diathermy to the macular hole (Dellaporta, 1953). Madroszkiewicz (1958) described an indirect method of sealing macular holes with retinal detachment and designed a special diathermy electrode to reach the macula. He applied diathermy near the macula and observed the formation of an exudate over the hole which was followed by closure, and was thus able to avoid direct cauterization of the macula. In our experience, however, if the macular hole was not entirely coagulated, the retina did not remain in place and the macular hole remained open. Strampelli (I957) exposed the retina to ultraviolet light and injected hypertonic saline into the space beneath Tenon's capsule to induce central chorioretinitis in cases in which the retina went back after rest in bed and binocular bandaging; for cases in which the retina remained detached after this preoperative measure, he advised paracentesis and the injection of air into the vitreous cavity. 
We have seen no cases of retinal detachment localized at the posterior pole except in patients with high myopia and posterior staphyloma. Nor have we observed any case in which the retina went fully back after binocular bandaging and rest in bed.

Schepens, Okamura, and Brockhurst (1957) used a polyethylene tube placed radially to buckle the macular area. He noticed that exposure is easier after drainage, and advised that the drainage should be done first.

Rosengren (1966) devised the silver ring and plomb method. A ring is attached round the limbus and a ball at the end of the arm exactly indents the macular hole. The surgeon waits a day or two for the subretinal fluid to absorb and then applies photocaogulation. The ring and plomb are removed after 4 weeks. No further report on this surgical technique and its results has been published.

Howard and Campbell ( 1969 ) described a simpler procedure. They used penetrating diathermy coagulation with drainage and saline injection and designed a special suction retractor to maintain a dry field during the operation. However, in many cases, the central area of the retina, especially the base of the posterior staphyloma, cannot be made flat even after repeated attempts. In the process of draining more fluid may be released than can be judged by clinical examination; the retina at the posterior pole remains elevated and may become even more elevated after the release of excessive amounts of fluid, and the eye becomes very soft.

\section{PRESENT INVESTIGATIONS}

In our first cases we reduced the volume of the eye either by an Arruga suture or a scleral infolding of the proper size to ensure perfect drainage and restore tension; this was followed by photocoagulation of the macular hole (Siam, I969). We have since encountered cases that could not be managed by this simple technique, in which the retina remained detached or even became more extensively detached after buckling and attempted drainage.

Extensive liquefaction of the vitreous at the posterior pole may explain how this occurs; fluid must pass directly from the vitreous through the hole to refill the intraretinal space at the posterior staphyloma. Diathermy or cryocoagulation will be useless in such cases and the retina will remain unattached. Photocoagulation would be out of the question because of the detachment. This was our experience in three of the nine cases, and Howard and Campbell ( 1969 ) have also reported a case in which "residual" subretinal fluid prevented adequate photocoagulation. The only solution under such circumstances would be the buckling of the macular area as described by Schepens and others (1957), Adams (I96r), and Blach (1966), but it is difficult to buckle this area for the following reasons:

(I) The extremely large eye and the difficulty of reaching the posterior pole particularly in the presence of a posterior staphyloma.

(2) The need to reach the optic nerve with all the ciliary nerves and vessels in the vicinity.

(3) The extreme thinness of the sclera at the posterior pole in these excessively myopic eyes and the difficulty of placing secure scleral sutures to retain and indent the episcleral silastic rod. The sutures easily cut the sclera and the vessels and nerves in this locality may be badly damaged. Accidental perforation with choroidal and sometimes vitreous haemorrhage may occur (Adams, 196r).

In managing detachments of this sort, therefore, cases will be found of two types:

(I) Favourable cases, in which the retina is completely replaced after a volume-reducing operation and complete drainage of the subretinal fuid.

The macular hole can be sealed by photocoagulation and usually requires a high minus 
contact lens (Usually -20 D sph.). It must be pointed out, however, that evacuation of the subretinal fluid has to be carefully carried out, using preferably a diathermy puncture rather than electrolysis (Siam, 1969). The puncture should be within the limits of the posterior staphyloma and preferably well behind it. This ensures perfect drainage. Also, as mentioned above, the buckling should be large enough to allow unexpectedly large amounts of the subretinal fluid to be released and firm tension restored with an absolutely flat retina at the base of the staphyloma. If this does not obtain the case is considered unfavourable.

(2) Unfavourable cases, in which the retina remains detached even after prolonged attempts at drainage.

The retina may be even more raised and the eye may become very soft with several radial folds on the buckle. In these cases a scleral macular buckle must beattempted; otherwise the operation will be a failure. Advantage is taken of the much smaller size of the eye

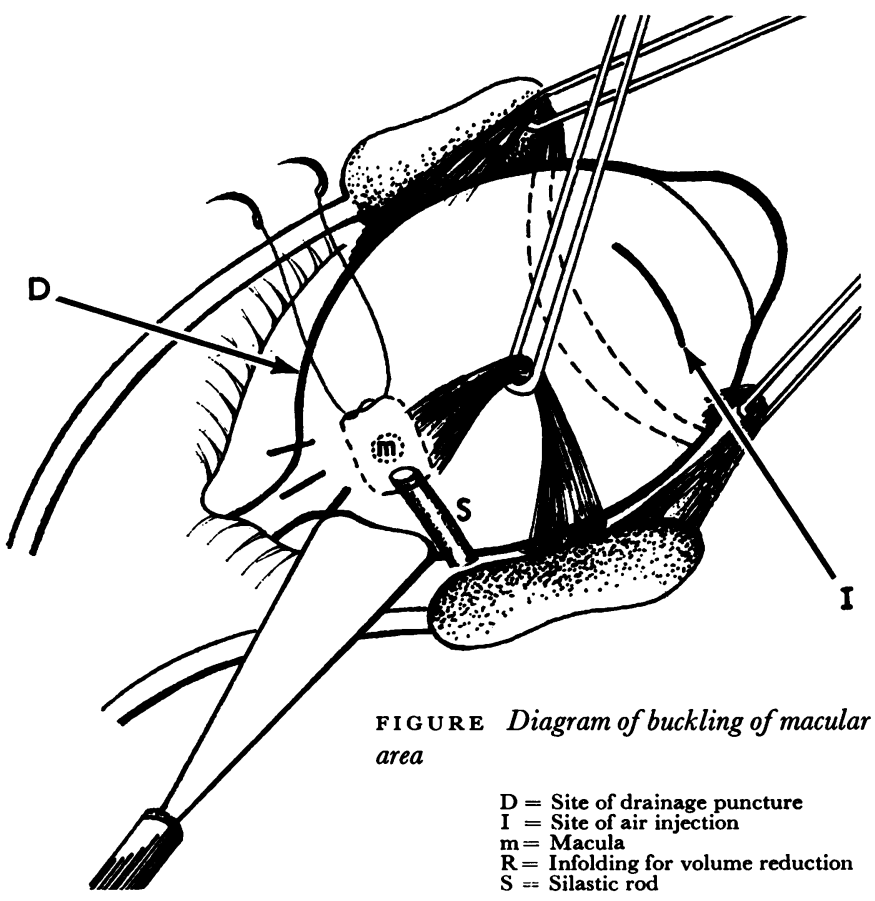
and the low tension to reach the posterior pole (Adams, I96I; Schepens and others, 1957). The soft eye is flattened medially and, with the aid of a 3-o silk suture under the inferior oblique muscle and lateral retraction, dissection is carefully carried out down to the sheath of the optic nerve. It will also be much easier to place the stitches. One end of the suture must be placed very carefully between the optic nerve sheath and the "macula" and the other between the macula and the inferior oblique muscle insertion. The suture must run at least $3 \mathrm{~mm}$. intrasclerally and the two ends must be $4 \mathrm{~mm}$. apart in order to stand tightening and produce a good buckle (Figure).

Cryocoagulation is then applied. A silastic rod $2 \mathrm{~mm}$. thick and $6 \mathrm{~mm}$. long is placed under the suture which is then tightened with artery forceps. The buckle here is vertical and not horizontal like that described by Schepens and others (1957). Cryotherapy is the best method of coagulating the macular hole since the freezing can be done under direct vision. Scleral indentation with the cryoprobe tip enables the operator to locate the macula exactly. Care has to be taken to avoid freezing the optic nerve, which may happen if the cryoprobe tip is not properly directed (Banks and Havener, 1970).

Although cryocoagulation, unlike diathermy, is not hampered by a wet field, freezing 
will occur in a shorter time and neighbouring structures will be less likely to be affected if the field be kept as dry as possible immediately before the application.

If, after tightening the suture, the ocular tension remains low, no further buckling should be performed since the globe will become deformed and the retina will be excessively folded inside and will remain detached. In these circumstances, air should be injected $6 \mathrm{~mm}$. from the limbus near the lateral rectus insertion. Because fluid sometimes continues to drain from the globe, the air should be injected very slowly and carefully until the drainage stops and the tension becomes firm. In some cases a great deal of fluid comes out and the fluid vitreous is largely replaced by air. In this way a good reposition will be obtained and the chance of cure is greatly enhanced.

\section{Summary}

Central retinal detachment due to macular holes has been encountered in highly myopic eyes with posterior staphylomata. Such cases occur in about I per cent. of retinal detachments. Two types of case may be distinguished:

(I) Favourable cases are those with a limited central retinal detachment which flattens perfectly after volume reduction and drainage of the bottom of the posterior staphyloma. This allows very limited and controlled macular photocoagulation, which preserves the function of the central area. These patients obtain the greatest benefit; most of them have useful vision and can get about unaided.

(2) Unfavourable cases are those with long-standing extensive central detachment and excessive vitreous liquefaction which do not flatten by volume reduction and drainage. The eye becomes very soft with the central retina still detached. These cases should be buckled in the macular area using a silastic rod.

Cryocoagulation allows direct visualization of the reaction in the macular area. Air injection is usually required at the end of the operation to complete the drainage and provide vitreous replacement. Air in the vitreous cavity will push the retina into the base of the posterior staphyloma and this will restore tension and provide support for the retina for several days.

\section{References}

ADAMs, s. T. (196r) Arch. Ophthal. (Chicago), 66, 528

ARruga, H. (1952) Trans. Amer. Acad. Ophthal. Otolaryng., 56, 355

BANKS, W. s., and HAVENER, W. H. (1970) Ibid., 74, 8o

BLACH, R. K. (1966) Discussion of Rosengren (1966)

Dellaporta, A. (1953) Klin. Mbl. Augenheilk., 122, 99

HOWARD, G. M., and CAMPBell, c. J. (1969) Arch. Ophthal. (Chicago), 81, 317

JUNGSCHAFFER, O. H. (197 I) Ibid., 86, I9

MADROSZKIEWICZ, M. (1958) Brit. F. Ophthal., 42, 739

PHILLIPS, C. I. (1958) Ibid., 42, 739

REgenBogen, L., and stein, R. (1968) Arch. Ophthal. (Chicago), 80, I 55

ROSENGREN, B. (1966) Trans. ophthal. Soc. U.K., 86, 49

SChEPENS, C. L., OKAMURA, I. D., and BrockhuRSt, R. J. (1957) A. M. A. Arch. Ophthal., 58, 797

SIAM, A-L. (1969) Brit. F. Ophthal., 53, 62

- (197 I) In "Proc. int. Symp. Fluorescein Angiography, Albi, I969", p. 592. Karger, Basel

STRAMPELli, B. (1957) Bull. Soc. franc. Ophtal., 70, 70 